\title{
Instructors' Acceptance of Learning Management Systems: A Theoretical Framework
}

\author{
Kamla Ali Al-Busaidi and Hafedh Al-Shihi \\ Sultan Qaboos University, AlKhod, Oman
}

\begin{abstract}
In the knowledge age, the use of the information technology (IT) tools including learning management systems (LMS) has became an imperative. The adoption rate of LMS in academic and training institutions is very promising worldwide. Learning Management system includes several tools that provide academic and training institutions efficient and effective means to support distance education and supplement their traditional way of teaching. LMS also provide academic insinuations mechanisms and tools to store, manage, and share its academic resources and knowledge. Instructors' acceptance is essential for the deployment of LMS. The success of LMS in any institution starts by instructors' acceptance, which in turns initiates and promotes learners' utilization of LMS. Consequently, the objective of this paper is to develop a theoretical framework for evaluating instructors' acceptance of LMS based on the Technology Acceptance Model. This framework provides a comprehensive look of the critical factors that influence the instructors' perceived ease of use and perceived usefulness of LMS and consequently the actual use. These critical factors are related to the instructor, organization, and technology. Instructor factors include self efficacy, attitude toward LMS, experience, teaching style and personal innovativeness. Organization factors include motivators, technology alignment, organization support, technical support and training. Technology factors include system quality, information quality and service quality.
\end{abstract}

Keywords: Learning Management Systems; E-Learning, Instructors' Acceptance

\section{Introduction}

The internet is now ubiquitous and with internet penetration rates ranging between as low as $5.6 \%$ in Africa and up to $74.4 \%$ in North America (Internet World Stats, 2009), any industry that does not embrace this technology will be seriously disadvantaged. As a matter of fact, not only the internet that is gaining popularity in education worldwide, all sorts of ICTs such as mobile technologies are also putting up robust momentum in the same field. For example, Ahonen and O'Reilly
(2007) found that South Koreans use hundreds of self-training services through their mobile phones to learn different things such as a new language, web design and mathematics which stress the high potential of mobile phones as a new medium in learning. Educators are forced to incorporate modern ICT tools as students become more IT savvy through what is called a Learning Management System (LMS).

Current reports presented that more than $90 \%$ of all responding universities and

Copyright (C) 2010 Kamla Ali Al-Busaidi, Hafedh Al-Shihi. This is an open access article distributed under the Creative Commons Attribution License unported 3.0, which permits unrestricted use, distribution, and reproduction in any medium, provided that original work is properly cited. Contact Author: Kamla Ali AlBusaidi, e-mail: kamlaa@squ.edu.om 
colleges in USA (Hawkins and Rudy, 2007) and about $95 \%$ of the same institutions in UK have adopted LMS for students and faculty use (Browne et al., 2006). The Middle East is no exception. E-learning and LMS are very promising both to corporations and educational institutions worldwide and in the Middle East (Lasrado, 2009). The Gulf Cooperation Council (GCC) countries have introduced several modernizing plans in the education sector (Robinson and Ally, 2009). For example, in Qatar a Blackboard Learning System has been introduced as part of the Carnegie Mellon University (Qatar Branch) website in 2006. In addition, investment in elearning in UAE forms about $45 \%$ of the market share (ElTartoussi, 2009) and in Saudi Arabia an LMS solution was developed locally called JUSUR, which incorporated many features like site management, and course and users management such as announcements, forums, quizzes and assignments(Al-Khalifa, 2009). Finally in Oman, a revamped educational portal was launched in December 2007 by the Ministry of Education, which enables parents to keep track of their children grades and absence records. It also has an LMS dedicated service where digital content and e-books along with audio and visual aids and files are shared with students and teachers electronically (Ministry of Education, 2009). Some academic institutions in Oman are also adopting LMS such as Sultan Qaboos University.

Despite the adoption rate worldwide, several issues must be faced in the adoption and diffusion of LMS/e-learning systems in any country regardless of how advanced or modest its ICT capability is. Albirini (2006) argued that e-learning is more than implanting computers and electronic devices in schools and classes. ElTartoussi (2009) indicated that successful education does not lie only on technology, but rather careful planning and adoption strategies must be closely investigated and that the adoption among users such as teachers and students is a vital concern. Obviously, the success of LMS in any academic institution starts by instructors' acceptance, which in turns initiates and promotes students' utilization of LMS in classes. In this respect, the adoption and dissemination of LMS initiatives among teachers and trainers is pretty much underresearched in the Middle East. This paper aims to bridge the gap and seek to frame a model to evaluate LMS from the instructors' perspective.

\section{Learning Management Systems (LMS)}

LMS is viewed differently among different players depending on how many features and tools are opted to be incorporated. Here, we provide a background of LMS including its definition, features, tools, benefits and applications.

\section{LMS Definition and Benefits}

LMS is relatively a new concept which is often confused with other concepts like elearning, digital learning, virtual learning and distance learning (Kritikou et al., 2008). All of these concepts represent modern advancements in the education process which in most cases involve the utilization of ICT tools and technologies (Albirini, 2006). LMS is defined as an online system that allows users to share information and collaborate online (Lonn and Teasley, 2009).

LMS is also perceived as a software application that uses the internet as a medium to support education and the learning process (Cavus and Momani, 2009). Particularly, LMS could be utilized by educational institutions as well as corporate ones with a major focus on managing the education process rather than merely delivering course and training materials electronically. LMS is also synonymous to elearning in terms of using the web inside classrooms to enhance the learning process (Rainer et al., 2007; Sridhar, 2005). Our focus in this paper is on LMS that is housed within an educational institution such as a university where the ultimate aim is to foster the learning process inside classrooms. In this respect, LMS overlaps broadly with the 
concept of virtual learning where the ultimate aim is to support learning inside classrooms through systemized tools and technologies (Albirini, 2006).

LMS provide essential advantages to any educational institution in general and instructors in specific. According to Mahdizadeh et al. (2008), e-learning tend to motivate students and teachers which in turn will increase students participations and interactions inside the classroom. The most cited benefits of e-learning and LMS are enhanced efficiency and cost-saving (Aczel et al., 2008; Naidu, 2006). In addition, LMS could accelerate the learning processes, and improve the effectiveness of communication between users (educators, staff, and students) (Cavus and Momani, 2009). Moreover, the use of ICT in education benefits the trainer and adopted organization in reducing learning times and increase job retention (Hall, 1997). Typically, LMS applications enable organizations to manage users, courses and instructors with testing capabilities and ability to generate reports, transcripts and notifications to students (Mahdizadeh et al., 2008).

LMS Tools for Instructors Several LMS and elearning systems are available in the market today such as ATutor, Moodle, WebCT, Learn.com, Joomla LMS, Krawler LMS and Blackboard. The mostly used applications are WebCT, Moodle and Blackboard, which are developed mostly using open source technology, Java EE based architecture, Microsoft .NET, PHP and MySQL (Cavus and Momani , 2009;Moodle, 2009). WebCT has been acquired by Blackboard Inc. in 2006 and is planned to be phased out to enrich Blackboard market share (OXFORD, 2009). The Blackboard system is a web based application that includes several learning enhancements tools such as course management and enables users to integrate it with student databases (Blackboard, 2009). On the other hand, Moodle is open source software that can be installed in any computer that runs Windows or Mac operating systems (Moodle, 2009). Despite vendors' assortment, all LMS solutions provide several essential tools for instructors. For example, Moodle offers instructors the ability to give online assignments, lessons, quizzes and surveys. It also incorporates essential web 2.0 tools like blogs where different users can have their own blogs (journals), and wikis which encourages teamwork among students to develop a collaborative class product. On the other hand, Blackboard offers similar but more process-oriented LMS tools such as Course Delivery application which includes a grade center to automate the grading process as well as a performance dashboard to track students' progress (Ball and Levy, 2008; Blackboard, 2009). Blackboard also offers a Community Engagement capability where parental involvement is supported as well as teaching beyond classrooms via online communities.

\section{Instructors' Acceptance of LMS}

Technology Acceptance User acceptance is a multidimensional attitude affected by various technical and social factors. Technology acceptance has been assessed in the literature based on perceived usefulness, user's satisfaction, intention to use, and/or actual usage of the technology. Various frameworks, such as those of Bailey and Pearson (1983), Davis (1989), DeLone and McLean (2003), Doll and Torkzadeh (1988), and Venkatesh and Davis (2000), investigate the determinants of this individuals' acceptance. Bailey and Pearson' (1983) and DeLone and McLean's (2003) models are very popular, however, they mostly focus on the effects of information system's technical characteristics on IS effectiveness. Davis's 1989 technology acceptance model (TAM) is a widely used model in the IS literature. TAM, see figure 1, indicates that two factors determine the attitude, intention and consequently the actual use of an information system; these factors are perceived usefulness (PU) and perceived ease of use (PEOU). TAM suggests that PU and PEOU are determined by external variables relative to the use of that specific information system. TAM2 model suggests that these external variables might be related to subjective norm, image, job relevance, output quality and result demonstrability (Venkatesh and Davis, 2000). 
Even though TAM2 provides common external variables that might affect the PU and PEOU and consequently the actual use of an information system, these external variables may not be the best fit for every information system including learning management systems (LMS). Even in the context of LMS, the external variables that might influence the technology acceptance vary according to whether the user is instructor or student.

The objective of this paper is to propose relevant external variables that influence the instructors' acceptance of LMS. The major issues that might influence instructors' acceptance of LMS might be related to the instructors' characteristics as proposed by (Ball and Levy, 2008), organization factors as proposed by Sumner and Hostetler (1999), and the technology as proposed by DeLone and McLean (2003).

Few studies investigated the instructors' acceptance of learning management systems such as Sumner and Hostetler (1999), Liaw et al. (2007) and Ball and Levy (2008). Sumner and Hostetler (1999) qualitatively investigated the importance of instructors characteristics (user type, current level of computing skills, extent of use of computing skills in teaching, and training needs), and organization factors (such as motivators, training, technology alignment, organization support, and technical support) on the instructors' adoption of technology in teaching. Liaw et al. (2007) investigated the effects of the quality of e-learning system on the perceived enjoyment, perceived usefulness and perceived self-efficacy, which consequently affect the instructor's intention to use the system. Ball and Levi (2008) investigated the effects of instructors' characteristics (such as computer selfefficacy, computer anxiety, and experience with the use of technology) on instructors' intention to use emerging educational technology. None of these highlighted studies, however, provided a comprehensive look into all these three issues: Instructors characteristics, organization factors and technology factors. This paper aims to provide an in depth examination of the major issues that might influence the instructors' acceptance based on these three areas (see Figure 2).

\section{Instructor Factors}

Few studies have investigated the instructor's characteristics on the acceptance and use of learning management systems (LMS) such as Ball and Levi (2008), Sumner and Hostetler (1999).

User self efficacy is highly recognized as an important issue in the acceptance of any information system including learning management systems. Self-efficacy is defined as "people's judgments of their capabilities to organize and execute courses of action required to attain designated types of performances" (Bandura, 1977). Thus, computer self-efficacy means individuals self-assessment of their ability to apply computer skills to accomplish their tasks (Compeau et al., 1995). Several empirical studies found significant effects of the computer self efficacy on the perceived usefulness on an information system (Vankatesh and Davis, 1996; Chau et al., 2001). In the context of e-learning system Ball and Levi found significant effect of instructors' acceptance (Ball and Levi, 2008).

Instructor's Attitude toward e-learning is another issue related to the acceptance of LMS. Instructors are the major drivers of LMS. Individuals' attitude should be considered in the investigation of LMS acceptance (Leidner and Jarvenpaa, 1995). Instructors attitude toward e-learning positively affect the outcomes of e-learning (Piccoli, 2001; Webster and Hackley, 1997).

Experience with the use of technology (EUT) also plays a major role with the acceptance of technology (Venkatesh and Davis, 2000). Individual's EUT is the individual's exposure to the technology as well as the skills and abilities that $\mathrm{s} / \mathrm{he}$ gains through using a technology (Thompson et al., 2006). In technology use in education, the current level 
of computer skills and extent of use of computing skills in teaching are important issues on instructors' acceptance (Sumner and Hostetler, 1999).

Instructor's teaching style is rarely investigated but it has been highlighted in the literature. Instructors with interactive teaching style are critical to the learning outcome (Wan et al., 2007; Webster and Hackley, 1997). Proposed classification of teaching style is: expert, formal authority, demonstrator/personal model, facilitator, and delegator as outlined by Grasha (2002).

Furthermore, personal innovativeness is another important issue that has been recently highlighted in the e-learning literature. Personal innovativeness in information technology context means person's attitude reflecting his tendency to experiment with and to adopt new information technologies independently of the communicated experience of others; innovative people may realize the usefulness and the ease of use of new systems more quickly than non-innovative people (Schillewaert et al., 2005). Several empirical studies confirmed the significance of personal innovativeness on technology acceptance such as Schillewaert et al. (2005) in the sales automation systems context and Raaij and Schepers (2008) in the e-learning context.

\section{Organization Factors}

Very limited theoretical and empirical studies captured the influence of organization factors on the acceptance of learning management systems generally and specifically instructor's acceptance. One of these studies is a qualitative study by Sumner and Hostetler (1999). They categorized the organization factors that may influence the use of technology in teaching in terms of motivators/demotivators, training, technology alignment, organization support and technical support.

Motivators are key factor on instructors' acceptance to integrate the technology in teaching. Motivators or incentives for instructors can be enforced by having the use of the technology a factor in nomination for teaching award, promotion and tenure (Sumner and Hostetler, 1999). Motivators can be also by providing instructors release time for their utilization.

Also, technology alignment is highlighted as a major issue on the acceptance of technology in business (Turban et al., 2008). An organization should clearly identify the goal of the technology and its importance for the organization's success. In the e-learning context, e-learning alignment refers to the alignment of the e-learning with the department and university curriculum (Sumner and Hostetler, 1999).

Organization support, represented by senior managers' support, is also important for instructors to accept and adopt LMS in their teaching. Management support of end-users significantly improves computer usage (Igbaria, 1991).

Moreover, providing instructors with technical support, in form of computer specialists, instructional design specialists and trained assistants, is essential to their acceptance (Sumner and Hostetler, 1999). Providing technical support is significant on promoting positive attitudes toward computer use (Igbaria, 1991).

Finally, providing end users with training is considered important; training can be in form of workshops, online tutorials, courses, and seminar. Facilitating conditions, measured by technical support, training and administrative support, indirectly affect teachers' acceptance of technology in education (Teo, 2009).

\section{Technology Factors}

Technology or Information systems factors can be related to the system quality, information quality and service support quality (DeLone and McLean, 2003). Elearning systems quality found to be significant on the instructors' perceived 
usefulness, perceived enjoyment and perceived self-efficacy which consequently affect their intention to use the system in the classroom (Liaw et al., 2007). Based on our knowledge, limited studies provide a comprehensive examination of the influence of technology factors on the instructors' acceptance. From the learners' perspective, found that perceived system quality factors (system quality information quality and service quality) affect directly el-earning users' satisfaction and intention to use, and indirectly on perceived usefulness (Roca et al., 2006).

System Quality refers to the characteristics of a system. Researchers, such as (Bailey and Pearson, 1983; DeLone and McLean, 2003; Seddon, 1997) have introduced several ways to measure system quality. In the context of e-learning, these system characteristics found significant on e-learning acceptance and use: reliability (Wan et al., 2007; Webster and Hackley, 1997), accessibility (Wan et al., 2007) and system's functionality, interactivity, and response (Pituch and Lee, 2006)

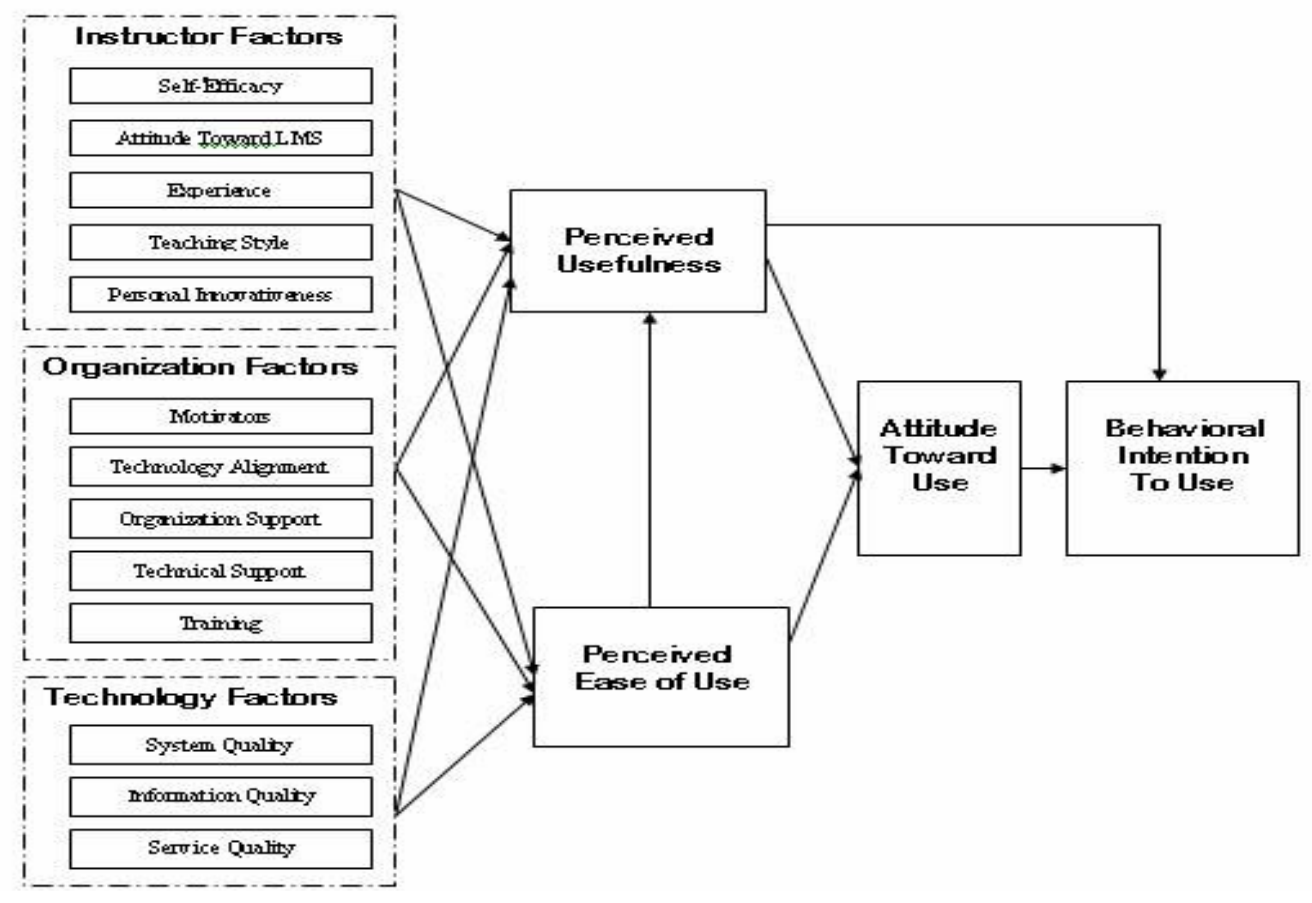

Fig 1. Proposed Instructor's LMS Acceptance Model
Information Quality refers to the perceived output produced by the system. The common characteristics of information quality include accuracy, relevance, timeliness, sufficiency, completeness, understandability, format and accessibility (Bailey and Pearson, 1983; Seddon, 1997). In the e-learning context, Roca et al. (2006) measured information quality by indicators related to relevance, timeliness, sufficiency, accuracy clarity and format, and proved information quality significance directly on satisfaction and indirectly on perceived usefulness.

Service Quality refers to the quality of support services provided to the system's end users. Common measurements of service quality are tangibles, reliability, responsiveness, assurance and empathy (Kettinger, and Lee, 1997; Parasuraman, 1988). In the e-learning context, Roca et al. (2006) assessed service quality by indicators related to responsiveness, reliability and empathy, and confirmed it's significant directly on satisfaction and indirectly on perceived usefulness. 


\section{Conclusion}

In the knowledge age, the use of the information technology (IT) tools including learning management systems (LMS) has became an imperative. The adoption rate of LMS in academic and training institutions is very promising worldwide. Learning Management system includes several tools that provide academic and training institutions efficient and effective means to support distance education and supplement their traditional way of teaching. LMS also provide academic insinuations mechanisms and tools to store, manage, and share its academic resources and knowledge. Instructors' acceptance is essential for the deployment of LMS. The success of LMS in any institution starts by instructors' acceptance, which in turns initiates and promotes learners' utilization of LMS.

Consequently, the objective of this paper was to examine the critical factors that might influence the instructors' perceived ease of use and perceived usefulness of LMS and consequently their actual use. These factors were categorized into three main categories which reflect the major elements of LMS utilization from the instructor point of view: instructor, organization, and technology see Figure2. These factors are related to the instructor, organization, and technology. Instructor factors include self efficacy, attitude toward LMS, experience, teaching style and personal innovativeness. Organization factors include motivators, technology alignment, organization support, technical support and training. Technology factors include system quality, information quality and service quality.

This study proposed a detailed framework that can be used by researchers and practitioners to assess the instructors' acceptance of LMS, and ensure successful deployment of LMS. Thus, future research should develop or adopt reliable and valid measurements for researcher and practitioners to evaluate these factors impact on instructors' acceptance of learning management systems. This study only proposed a theoretical model, thus empirical investigations are also needed to verify the effects of these factors. Future qualitative studies (such as case analysis, interviews etc) might reveal some further insights on these factors. However, further quantitative rigorous studies are needed to validate the model and generalize it. In addition, detailed treatment of the relationships between the drawn factors is beyond the scope of this study which also provides an opportunity for further studies. Furthermore, cross-cultural evaluation of the Moodle may add useful insights.

\section{Acknowledgment}

This paper is a part of Sultan Qaboos University granted research project.

\section{References}

Aczel, J. C., Peake, S. R. and Hardy, P. (2008), 'Designing Capacity-Building in E-Learning Expertise: Challenges and Strategies,' Computers \& Education (50), 499-510.

Ahonen, T. and O'Reilly, J. (2007), Digital Korea, Futuretext, London.

Albirini, A. (2006), 'Teachers' Attitudes toward Information and Communication Technologies: The Case of Syrian EFL Teachers,' Computers \& Education (47), 373398.

Al-Khalifa, H. (2009), 'JUSUR: The Saudi Learning Management System,' the 2nd Annual Forum on e-Learning Excellence in the Middle East, 2009, Dubai, UAE.

Bailey, J., and Pearson, S. (1983), 'Development Of A Tool For Measuring And Analyzing Computer User Satisfaction,' Management Science, 29(5), 530-545.

Ball, D. and Levy, Y. (2008), 'Emerging Educational Technology: Assessing the 
Factors that Influence Instructors' Acceptance in Information Systems and Other Classrooms,' Journal of Information Systems Education, 19(4), 431-443.

Bandura, A. (1977). 'Self-Efficacy: Toward a Unifying Theory of Behavioral Change,' Psychological Review, 84(2), 191-215.

Blackboard. (2009). Engaging Learners For Engaging Learning. [Online]. Blackboard. [September 7th, 2009]. Available: http://www.blackboard.com/TeachingLearning/Learn-Platform.aspx.

Browne, T., Jenkins, M., and Walker, R. (2006),' A Longitudinal Perspective Regarding The Use of Vles By Higher Education Institutions In The United Kingdom,' Interactive Learning Environments, 14(2), 177-192.

Cavus, N. and Momani, A. M. (2009), 'Computer Aided Evaluation of Learning Management Systems,' Procedia Social and Behavioral Sciences, 1, 426-430.

Chau, Y., Patrick, K. and Hu, J. (2001), 'Information Technology Acceptance by Individual Professionals: A Model Comparison Approach,' Decision Sciences, 32(4), 699-718.

Compeau, R., Deborah, A., Higgins, A. and Christopher. (1995), 'Computer Self-Efficacy: Development of a Measure and Initial Test,' MIS Quarterly, 19(2), 189-211.

Davis, F.D. (1989), 'Perceived usefulness, perceived ease of use, and user acceptance of information technology,' MIS Quarterly (13), 319-339.

DeLone, W., and McLean, E. (2003), 'The DeLone and McLean Model of Information Systems Success: A ten-year update,' Journal of Management Information Systems, 19(4), 9-30.
Doll and Torkzadeh, G. (1988), 'The Measurement of End User Computing Satisfaction,' MIS Quarterly, 12(2), 259-274.

ElTartoussi, I. (2009), 'Networked Readiness in the United Arab Emirates,' the 2nd Annual Forum on e-Learning Excellence in the Middle East, 2009, Dubai, UAE.

Grasha, A. F. (2002), Teaching with Style, Alliance Publisher, USA.

Hall, B. (1997), Web-Based Training Cookbook, Wiley, NJ.

Hawkins, B. L., and Rudy, J. A. (2007), 'Educause Core Data Service. Fiscal Year 2006 Summary Report'. Educause, CO, USA.

Igbaria, M. (1990), 'End-User Computing Effectiveness: A structural equation model,' OMEGA, 18(6), 637.

Internet World Stats. (2009). World Internet Users and Population Stats. [Online]. Internet World Stats. [September 7th, 2009]. Available:

http://www.internetworldstats.com/stats.ht $\mathrm{m}$.

Kettinger, W.J., and Lee, C.C. (1997), 'Pragmatic Perspectives on the Measurement of Information Systems Service Quality,' MIS Quarterly, 21(2), 223-239.

Kritikou, Y., Demestichas, P., Adamopoulou, E., Demestichas, K., Theologou, M., and Paradia, M. (2008), 'User Profile Modeling In The Context of Web-Based Learning Management Systems,' Journal of Network and Computer Applications, 31, 603-627.

Lasrado, F. (2009), 'Attitudes towards eLearning: Exploratory Evidence from UAE, ' the 2nd Annual Forum on e-Learning Excellence in the Middle East, 2009, Dubai, UAE.

Leidner, D and Jarvenpaa, S. (1995), 'The Use of Information Technology to Enhance Management School Education: A theoretical view," MIS Quarterly, 19, 265-291. 
Liaw, S., Huang, H, and Chen, G. (2007),'Surveying Instructor and Learner Attitudes toward e-Learning,' Computers \& Education, 49, 1066-1080.

Lonn, S., and Teasley, S. D. (2009), 'Saving Time in Innovating Practice: Investigating Perceptions and Uses of Learning Management Systems," Computers \& Education, 53, 686-694.

Ministry of Education. (2009). Education Portal Services Booklet. [Online]. Ministry of Education. [September 8th, 2009]. Available: http://www.moe.gov.om/portal/sitebuilder/ sites/eps/Arabic/MOE/eEducation.pd.

Mahdizadeh, H., Biemans, H. and Mulder, M. (2008). (2008), 'Determining Factors of the Use of E-Learning Environments by University Teachers," Computers \& Education, 51, 142-154.

Moodle. (2009). About Moodle. [Online]. Moodle. [September 8th, 2009]. Available: http://docs.moodle.org/en/About_Moodle.

Naidu, S.(2006), E-Learning A Guidebook Of Principles, Procedures and Practices, 2nd revised edition, Commonwealth Educational Media Center for Asia (CEMCA), New Delhi, India.

OXFORD University Press. (2009). Learn about Virtual Learning Environment, [Online]. OXFORD University. [September 8th, 2009]. Available: http://www.oup.com/uk/orc/learnvle.

Parasuraman, A., Zeithaml, V.A., and Berry, L. (1988), 'SERVQUAL: A multiple-item scale for measuring customer perceptions of service quality,' Journal of Retailing, 64(1), 12-40.

Piccoli, G., Ahmad, R., and Ives, B. (2001), 'Web-Based Virtual Learning Environments: A research framework and a preliminary assessment of effectiveness in basic IT skill training,' MIS Quarterly, 25(4), 401-426.
Pituch, K. and Lee, Y. (2006), 'The Influence of System Characteristics on e-learning Use," Computers \& Education, (47), 222-244.

Raaij, E. and Schepers, J. (2008), 'The Acceptance and Use of A Virtual Learning Environment in China,' Computers \& Education (50), 838-852.

Rainer, R. K., Turban, E. and Potter, R. E. (2007), Introduction to Information Systems: Supporting and Transforming Business, Wiley, NJ, USA.

Robinson, M. and Ally, M. (2009). 'Transition to e-Learning in a Gulf Arab Country," In: The 2nd Annual Forum on e-Learning Excellence in the Middle East, 2009, Dubai, UAE.

Roca, J., Chiu, C. and Martinez, F. (2006), 'Understanding e-learning Continuous Intention: An extension of the technology acceptance model," Int. J. Human-Computer Studies, 64, 683-696.

Schillewaert, N., Ahearne, M. J., Frambach, R. T., and Moenaert, R. K. (2005), 'The adoption of information technology in the sales force,' Industrial Marketing Management, 34, 323336.

Seddon, P.B. (1997), 'A respecification and extension of the DeLone and McLean model of IS success," Information Systems Research, 8(3). 240-253.

Sridhar, S. (2005), 'E-government - A Proactive Participant For e-Learning in Higher Education,' Journal of American Academy of Business, 7(1), 258- 268.

Sumner, M. and Hostetler, D. (1999), 'Factors Influencing the Adoption of Technology in Teaching,' The Journal of Computer Information Systems, 40(1), 81-87

Teo, T. (2009), 'Modeling Technology Acceptance In Education: A study of preservice teachers,' Computers \& Education, 52, 2009, pp. 302-312. 
Thompson, R., Compeau, R. Deborah, and Higgins, C. (2006), 'Intentions to Use Information Technologies: An Integrative Model,' Journal of Organizational and End User Computing, 8(3), 25-47.

Turban, E., Leidner, D., McLean, E., and Wetherbe, J. (2008). Information Technology for Management, John Wiley, USA.

Venkatesh, V., and Davis, F. (2000), 'A Theoretical Extension of the Technology Acceptance Model: Four longitudinal,' Management Science, 46(2), 186-204.

Wan, Z., Fang, Y and Neufeld, H. (2007), 'The Role of Information Technology in Technology-Mediated Learning: A review of the past for the future,' Journal of Information Systems Education, 18(2), 183-192.

Webster, J. and Hackley, P. (1997), 'Teaching effectiveness in technology-mediated distance learning,' Academy of Management Journal, 40(6), 1282-1309. 